
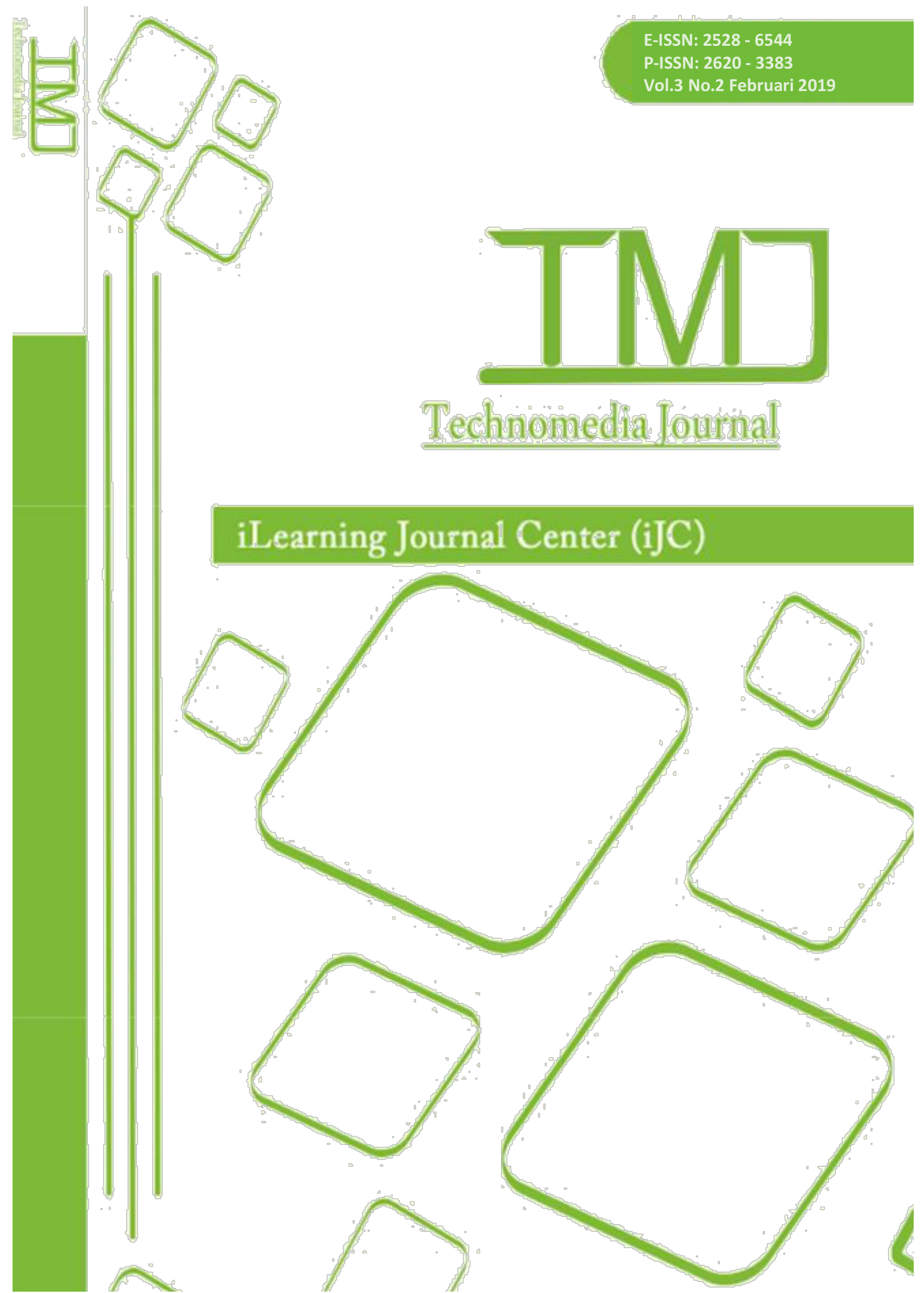


\title{
Pemanfaatan Indeksasi Mendeley Sebagai Media Pengenalan Jurnal STT Yuppentek
}

\author{
Indri Handayani ${ }^{1}$ \\ Erick Febriyanto $^{2}$ \\ Teguh Arya Yudanto ${ }^{3}$ \\ Dosen Universitas Raharja ${ }^{1,2}$ \\ Mahasiswa Universitas Raharja ${ }^{3}$ \\ E-mail: indri@raharja.info ${ }^{1}$,erick@raharja.info ${ }^{2}$,teguh@raharja.info ${ }^{3}$
}

\begin{abstract}
ABSTRAK
Karya ilmiah atau jurnal pada STT Yuppentek saat ini masih kurang dikenal secara global dan indeksasi merupakan elemen penting untuk meningkatkan popularitas karya ilmiah atau jurnal. Mendeley adalah sebuah perangkat lunak yang dikhususkan untuk mengintegrasikan citation \& reference manager ke dalam sebuah jejaring sosial, dimana peneliti di berbagai belahan dunia dapat berkolaborasi dan melakukan sharing data penelitian. Mendeley dapat diakses melalui aplikasi desktop, web, dan mobile dengan menyediakan full-text search terhadap seluruh paper dalam database dan berbagi dokumen pada database dengan pengguna lain serta sinkronisasi pustaka referensi dengan data yang tersimpan di server web Mendeley. Namun terdapat beberapa permasalahan yang dihadapi dalam penelitian pada STT Yuppentek ini yaitu minimnya kualitas serta keaslian dari karya ilmiah atau jurnal, serta popularitas karya ilmiah atau jurnal STT Yuppentek di kalangan global. Penelitian ini dilakukan dengan menggunakan metode pengumpulan data, analisis permasalahan dan analisis kebutuhan karena metode tersebut sesuai dengan penelitian ini untuk mengidentifikasi masalah yang dihadapi. Hasil dari penelitian ini adalah menerapkan aplikasi pengelolaan kutipan dan referensi jurnal STT Yuppentek dan meningkatkan popularitas karya ilmiah atau jurnal STT Yuppentek secara global.
\end{abstract}

Kata Kunci: Indeksasi, Jurnal STT Yuppentek, Mendeley.

\begin{abstract}
Scientific works or journals at STT Yuppentek are currently less globally known and indexation is an important element to increase the popularity of scientific papers or journals. Mendeley is a software that is devoted to integrating citation \& reference managers into a social network, where researchers in various parts of the world can collaborate and share research data. Mendeley can be accessed through desktop, web and mobile applications by providing full-text search for all papers in the database and sharing documents on the database with other users and synchronizing reference libraries with data stored on Mendeley's web server. However, there are several problems faced in the research at STT Yuppentek, namely the lack of quality and authenticity of scientific works or journals, and the popularity of scientific works or STT Yuppentek journals in global circles. This research was carried out using data collection methods, problem analysis and needs analysis because the method was in accordance with this study to identify the problem at hand. The results of this study are applying the
\end{abstract}


management application of quotes and references from the STT Yuppentek journal and increasing the popularity of scientific papers or STT Yuppentek journals globally.

Keywords: Indexation, Yuppentek STT Journal, Mendeley.

\section{PENDAHULUAN}

Jurnal elektronik merupakan representasi elektronik sederhana dari sebuah jurnal cetak, dimana jurnal elektronik ditulis dan disebarkan melalui internet dimana hasilnya berupa data digital. Dalam sebuah jurnal atau karya ilmiah sangat diperlukan indeksasi, dimana indeksasi berperan penting untuk meningkatkan popularitas karya ilmiah atau jurnal.

Jurnal STT Yuppentek merupakan media untuk publikasi tulisan asli atau karya ilmiah yang berkaitan dengan bidang Ilmu Teknik Mesin, Teknik Elektro dan Teknik Industri dalam Bahasa Indonesia Maupun Bahasa Inggris pada kampus STT YUPPENTEK dimana penerbitan dilaksanakan dua kali yaitu pada bulan April dan Oktober, Jurnal STT Yuppentek disediakan sebagai fasilitas bagi setiap anggota komunitas iLearning (terbuka) sebagai media untuk mempublikasikan temuan atau penelitiannya secara mudah melalui media online.

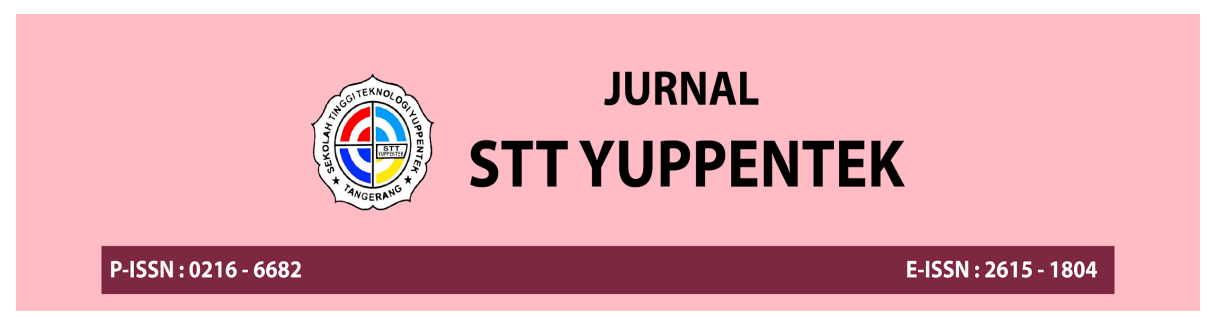

Gambar 1. Jurnal STT Yuppentek

Pengelola Jurnal STT Yuppentek saat ini dituntut untuk tidak hanya dapat melakukan publish jurnal saja namun harus dapat melakukan indeksasi untuk jurnal yang sedang dikelolanya, hal ini diperlukan agar penelitian dari Jurnal STT Yuppentek dapat dikenal secara global di kalangan peneliti.

\section{PERMASALAHAN}

Pada tahap permasalahan, yaitu melakukan identifikasi permasalahan yang dihadapi pada jurnal atau karya ilmiah STT Yuppentek yang dapat menghambat visibilitas artikel sehingga tidak mendukung gerakan open access journal dan minimnya pengunjung (visitor) pada Jurnal STT Yuppentek.

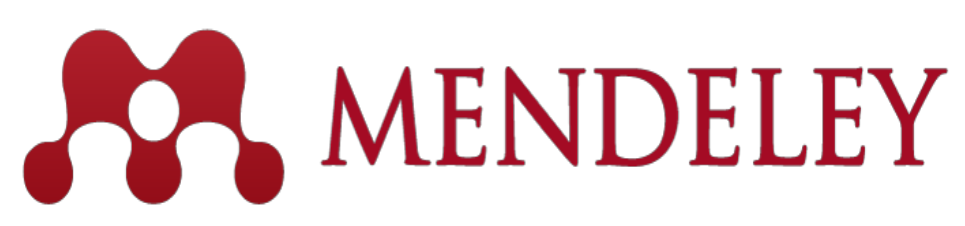

Gambar 2. Logo Mendeley

Mendeley adalah sebuah perangkat lunak yang dikhususkan untuk mengintegrasikan citation \& reference manager ke dalam sebuah jejaring sosial, dimana peneliti di berbagai belahan dunia dapat berkolaborasi dan melakukan sharing data penelitian. Dengan 
pemanfaatan indeksasi pada Mendeley penulis dapat meningkatkan kualitas serta keaslian dari karya ilmiah atau jurnal, membuat pengelompokan berdasarkan topik atau kategori tertentu, serta sebagai wadah atau tempat sharing untuk meningkatkan popularitas karya ilmiah secara global.

\section{METODE PENELITIAN Pengumpulan Data}

Metode pengumpulan data merupakan suatu teknik atau cara yang dilakukan penulis untuk mengumpulkan data yang dibutuhkan dalam penelitian, mendapatkan serangkaian informasi, serta untuk melakukan penelitian dengan tercapainya tujuan yang diharapkan. Adapun metode pengumpulan data yang penulis terapkan adalah sebagai berikut :

1. Metode Observasi (Pengamatan)

Observasi adalah proses yang dilakukan penulis untuk terlibat secara langsung ke lapangan tujuannya yaitu memperoleh data. Metode pengamatan atau metode observasi pada sistem ini dilakukan pada STT Yuppentek dengan cara mengumpulkan data, informasi, dan mempelajari catatan serta dokumen yang ada. Hasil yang didapatkan yaitu dibutuhkan sebuah sistem yang dapat meningkatkan popularitas karya ilmiah atau Jurnal STT Yuppentek.

2. Metode Wawancara (Interview Research)

Wawancara merupakan suatu cara untuk mengumpulkan data dengan mengajukan beberapa pertanyaan kepada narasumber untuk memperoleh keterangan atau informasi yang relevan dan akurat.

3. Studi Pustaka (Literature Review)

Studi pustaka merupakan salah satu teknik pengumpulan data sebagai referensi yang bertujuan untuk mendapatkan informasi lebih ke arah penelitian-penelitian serupa yang relevan dengan cara membaca, mempelajari, dan mendalami literatur-literatur. Sehingga penulis lebih mudah memahami tentang penerapan dan pemanfaatan Indeksasi Mendeley bagi Jurnal STT Yuppentek.

\section{Analisis Permasalahan}

Menurut Sunarya, dkk. (77:2019), "Analisis dilakukan untuk mengklasifikasikan data ke dalam kelas-kelas". Ketepatan dalam menganalisa data akan menentukan pengambilan keputusan. Menurut Sunarya, dkk. (492:2018), "Kelebihan dari hasil proses analisis yang cepat ini sangat berguna khususnya dalam menghadapi era persaingan dalam menyajikan data".

Permasalahan pada penelitian ini dilakukan pada STT Yuppentek dengan cara menentukan dan merumuskan permasalahan yang dihadapi. Pada penerapannya, Jurnal STT Yuppentek masih belum dikenal luas oleh kalangan global membuat Jurnal STT Yuppentek belum dapat bersaing dengan jurnal-jurnal lain dan masih jauh dari akreditasi jurnal. Keadaan seperti ini mengharuskan adanya perubahan yaitu dengan mendaftarkan Jurnal STT Yuppentek pada indeksasi mendeley yang dapat mendukung agar meminimalisir tingkat plagiat pada jurnal dan meningkatkan kualitas karya ilmiah atau jurnal serta dapat meningkatkan popularitas jurnal secara global. Adapun beberapa permasalahan yang dihadapi pada penelitian ini sebagai berikut :

1. Minimnya kualitas dan keaslian dari setiap karya ilmiah atau jurnal STT Yuppentek.

2. Sulitnya membuat pengelompokan berdasarkan topik/kategori karya ilmiah.

3. Kurangnya popularitas karya ilmiah di kalangan luas. 


\section{Analisis Kebutuhan}

Setelah melakukan identifikasi beberapa permasalahan yang terjadi pada sistem yang berjalan, terdapat alternatif pemecahan masalah yang dihadapi yaitu dengan menerapkan indeksasi pada Mendeley, karena Indeksasi Mendeley memiliki kelebihan diantaranya :

1. Backup dan sinkronisasi data dari beberapa komputer dengan akun online.

2. Import dokumen dan makalah penelitian dari situs-situs eksternal seperti PubMed, Google Scholar, dll.

3. Terdapat Fitur Filtering.

4. Terdapat Fitur jejaring sosial.

\section{Literature Review}

1. Penelitian yang dilakukan Rahmawati (2018) dengan pembahasan Analisis Indeksasi Jurnal Ilmiah Bidang Pertanian Indonesia di DOAJ, Penelitian ini bertujuan untuk mendeskripsikan bagaimana indeksasi jurnal ilmiah bidang pertanian yang terbit di Indonesia pada DOAJ. Metode penelitian yang digunakan adalah penelitian kepustakaan. Metode kepustakaan yang dimaksud adalah dengan melakukan penelusuran dokumen-dokumen secara online. Hal ini dikarenakan indeksasi jurnal yang tersedia dilakukan secara online. Penelusuran dilakukan pada portal DOAJ (http://doaj.org). Hasil penelusuran kemudian disajikan dalam bentuk deskriptif yang dilengkapi dengan tabel dan gambar berdasarkan biaya penerbitan, penerbit, tahun terdaftar pada DOAJ, proses review, dan lisensi.

2. Penelitian yang dilakukan oleh Cut Rahmawati, Meliyana, Yuliana, dan Helwiyah Zain (2018) dengan pembahasan tentang Pelatihan Software Mendeley Dalam Peningkatan Kualitas Artikel Ilmiah Bagi Dosen. Publikasi pada jurnal internasional dan jurnal nasional menuntut artikel ditulis secara ilmiah dan menggunakan reference manager yang baik. Dalam hal ini masih banyak dosen yang mengalami kesulitan dalam menyusun kutipan dan daftar pustaka. Pada saat merubah kutipan dan daftar pustaka pada style yang berbeda masih dilakukan secara manual. Pelatihan ini didasari pada kesulitan dosen dalam melakukan publikasi ilmiah pada jurnal internasional bereputasi dan jurnal nasional yang terakreditasi khususnya dalam membuat daftar pustaka dan menulis kutipan. Pelatihan yang dilaksanakan berupa pelatihan software Mendeley pada artikel ilmiah dosen. Software Mendeley banyak memberi kemudahan dalam meningkatkan kualitas tulisan artikel ilmiah yaitu kemudahan bagi dosen dalam membuat kutipan dan daftar pustaka.

3. Penelitian yang dilakukan oleh Wahyudin Darmalaksana (2017) dengan pembahasan tentang Panduan publikasi ilmiah: Perangkat aplikasi, standar penulisan dan etika kepengarangan. penelitian ini bermaksud mengusulkan panduan publikasi ilmiah untuk diberlakukan di lingkungan internal Pusat Penelitian dan Penerbitan, Lembaga Penelitian dan Pengabdian kepada Masyarakat (LP2M) UIN Sunan Gunung Djati Bandung. Penelitian ini menggunakan metode kualitatif ketika menelaah sumber kepustakaan sebagai bahan panduan publikasi ilmiah yang memungkinkan implementatif berdasarkan kenyataan di lapangan sehingga dapat dilakukan penarikan kesimpulan. Dalam penelitian ini ditemukan hasil bahwa publikasi ilmiah telah serba elektronik yang menuntut kemampuan praktis penguasaan aplikasi perangkat lunak 
penulisan di samping substansi tulisan dan etis kepengarangan bersama publikasi ilmiah.

4. Penelitian yang dilakukan oleh Sri Junandi (2018) yang membahas tentang Pengelolaan Jurnal Elektronik Bidang Perpustakaan Menuju Jurnal Terakreditasi. Pengelolaan jurnal ilmiah dalam rangka mencapai jurnal ilmiah terakreditasi nasional memerlukan Sistem Manajemen dan Pengelolaan Jurnal yang efektif dan efisien. Sistem Manajemen dan Pengelolaan Jurnal ini harus mengacu kepada instrumen-instrumen dan kriteriakriteria yang disyaratkan oleh akreditasi jurnal nasional dan lembaga pengindeks internasional. Pengelola Berkala Ilmu Perpustakaan dan Informasi telah menerapkan sebagian besar instrumen dan kriteria yang ditetapkan sesuai Peraturan Direktur Jenderal Dikti Nomor 1 Tahun 2014 tentang Pedoman Akreditasi Terbitan Berkala Ilmiah.

5. Penelitian yang dilakukan oleh Nurlaila Suci Rahayu Rais, Ruli Supriati, dan Siti Ika Danti (2018) yang membahas tentang Instalasi Open Journal System (OJS) Versi 3 Sebagai Pendukung Kegiatan Pengelolaan dan Publikasi Jurnal Ilmiah. Open Journal System (OJS) merupakan perangkat lunak open source yang digunakan untuk mengelola jurnal ilmiah secara online. Tujuan penelitian ini adalah untuk memahami cara instalasi OJS versi 3 serta untuk mengetahui kelebihan OJS versi 3 yang dapat mendukung kegiatan pengolahan dan publikasi jurnal ilmiah elektronik (e-journal). Metode penelitian yang digunakan yaitu analisis kebutuhan dalam proses instalasi OJS dan flowchart yang menjelaskan tahap-tahap instalasi OJS.

6. Penelitian yang dilakukan oleh Sudaryono, Untung Rahardja, dan Desy Apriani (2019) yang membahas tentang The CICES Journal Governance Performance Improvement on Quality Of Current Issues (Case Study of STMIK RAHARJA). Jurnal CICES adalah salah satu jurnal di STMIK Raharja, yang diterbitkan 1 tahun 2 kali pada bulan Februari dan Agustus, masalah yang terjadi adalah tidak adanya jurnal online terindeks google scholar, dan tidak ada ringkasan informasi untuk membuat keputusan dan kesulitan calon penulis mendapatkan informasi tentang jurnal CICES. Untuk mengatasi masalah ini, dilakukan penelitian yang mengembangkan sistem untuk meningkatkan tata kelola jurnal CICES pada kualitas dan kualitas yang dipublikasikan dengan menggunakan analisis SWOT dan metode Statistik Produk dan Layanan Solusi (SPSS) yang dirasa dapat membantu dalam manajemen data. kemudian ditransformasikan dalam bentuk iMe di STMIK Raharja, diharapkan dapat mengatasi kendala yang ada, dengan memberikan informasi yang mendukung sistem pengambilan keputusan dalam Jurnal Publikasi.

7. Penelitian yang dilakukan oleh Nilasari Mukti W dan Erma Suryani (2018) dengan pembahasan tentang Analisis Kepuasan Pengguna Website Jurnal Online dengan Menggunakan Metode Webqual (Studi Kasus Buletin Penelitian Sistem Kesehatan). Penelitian ini menjabarkan faktor-faktor yang mempengaruhi tingkat kepuasan dan mengukur tingkat kepuasan penggunaan jurnal online. Tujuan yang ingin dicapai dalam penelitian ini adalah untuk mendeskripsikan hubungan atau pengaruh antara kualitas website e-journal buletin penelitian sistem kesehatan dengan tingkat kepuasan pengguna (User Satisfaction), untuk mendeskripsikan hubungan atau pengaruh antara kualitas website e-journal buletin penelitian sistem kesehatan dengan tingkat intensitas pengguna (Use Intensity), untuk mendeskripsikan hubungan atau pengaruh antara 
tingkat kepuasan pengguna (User Satisfaction) dengan tingkat intensitas pengguna (Use Intensity).

8. Penelitian yang dilakukan oleh Ahmat Josi (2017) dengan pembahasan tentang PERANCANGAN DAN IMPLEMENTASI E-JURNAL PADA UNIT PENELITIAN DAN PENGABDIAN MASYARAKAT (UP2M) STMIK PRABUMULIH. Penelitian ini menjabarkan tentang penerapan dalam sistem pengelolaan jurnal konvensional atau yang sebelumnya dilakukan secara manual atau tercetak, sehingga belum bisa diakses oleh masyarakat luas. Maka dari itu diperlukan suatu sistem yang dapat mengelola jurnal elektronik agar dapat menyelesaikan persoalan yang dihadapi. Tujuan dari penelitian ini adalah menyelesaikan persoalan (problem) pada UP2M STMIK prabumulih dengan memanfaatkan kesempatan (opportunities) yang ada.

9. Penelitian yang dilakukan oleh Untung Rahardja, Eka Purnama Harahap, Shylvia Ratna Dewi (2019) yang berjudul The Strategy of Enhancing Article Citation and H-Index on SINTA to Improve Tertiary Reputation. Penelitian ini menjabarkan tentang adanya sistem Google Scholar atau Google Cendekia yang mendukung adanya Sitasi atau Kutipan (Daftar Pustaka) dalam pembuatan suatu karya ilmiah. Karena pada dasarnya mengutip sebuah tulisan atau artikel yang berupa hasil karya penelitian orang lain merupakan salah satu bentuk komunikasi ilmiah yang dilakukan penulis atau peneliti satu sama lainnya. Dengan adanya sitasi atau kutipan yang ada pada Google Scholar ini dapat mengidentifikasi jumlah sitasi dan $\mathrm{H}$-Index yang dimiliki oleh para peneliti atau penulis jurnal dan juga dapat mengidentifikasi jumlah score atau ranking suatu Perguruan Tinggi pada SINTA (Science and Technology Index) RISTEKDIKTI. Dari penelitian ini juga dapat disimpulkan bahwa dengan adanya strategi peningkatan sitasi artikel dan H-Index mampu memberikan kontribusi dalam kemajuan reputasi sebuah Perguruan Tinggi atau Institusi.

10. Penelitian yang dilakukan oleh Agus Perdana Windarto, Dedy Hartama, Anjar Wanto, Iin Parlina (2018) yang membahas tentang Pelatihan Pemanfaatan Mendeley Desktop Sebagai Program Istimewa Untuk Akademisi Dalam Membuat Sitasi Karya Ilmiah Aplikasi desktop mendeley merupakan aplikasi yang dimaksudkan untuk memudahkan pembuatan kutipan dan daftar perpustakaan yang biasa digunakan oleh penulis. aplikasi ini juga dapat digunakan untuk mengelola file artikel jurnal online yang merupakan hasil karya ilmiah. Kegiatan pelatihan yang dilakukan dalam kegiatan Pengabdian Masyarakat menunjukkan bahwa peserta memiliki pemahaman materi dan potensi untuk menjadikan manajer referensi lebih baik dan maksimal dengan memanfaatkan aplikasi desktop mendeley.

Berdasarkan 10 literatur diatas dapat disimpulkan bahwa mendeley adalah sebuah perangkat lunak yang dikhususkan untuk mengintegrasikan citation \& reference manager ke dalam sebuah jejaring sosial, dimana peneliti di berbagai belahan dunia dapat berkolaborasi dan melakukan sharing data penelitian. 


\section{HASIL DAN PEMBAHASAN}

Implementasi

Pada tahap ini yaitu proses implementasi pendaftaran indeksasi mendeley, dengan melakukan tahapan sebagai berikut :

\section{Mengunjungi website Mendeley}

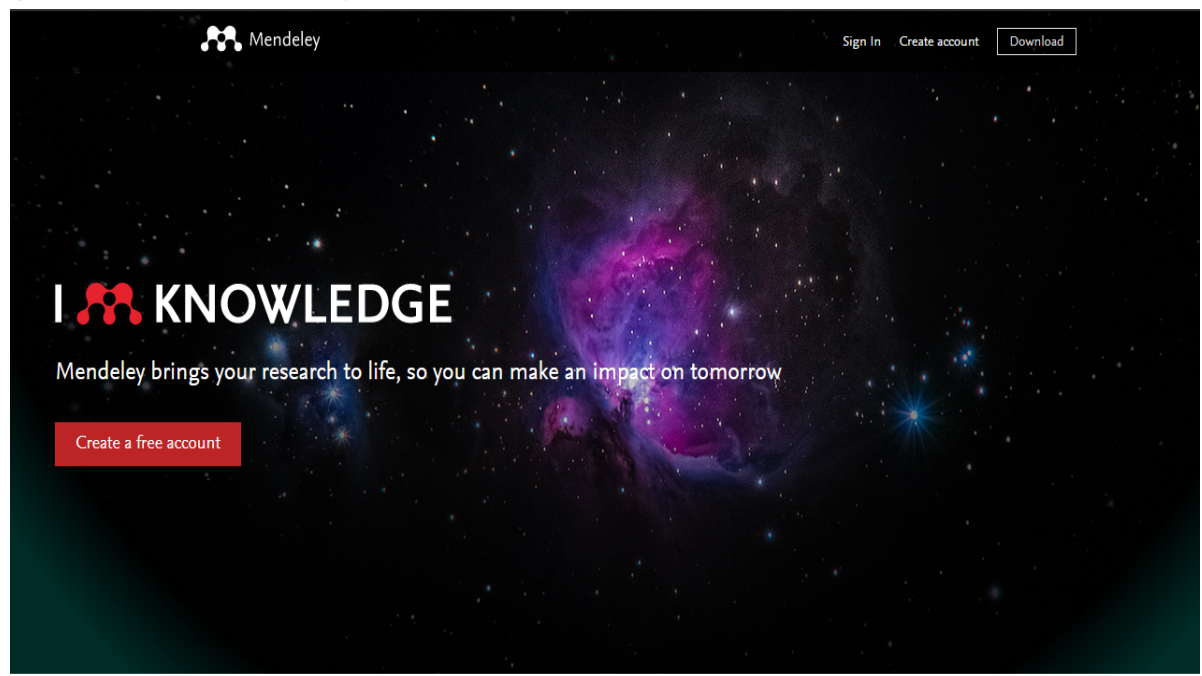

Gambar 3. Tampilan Halaman Utama Mendeley

(Sumber : https://www.mendeley.com/)

Pada Gambar 3. merupakan tampilan halaman utama dari Mendeley. Terdapat tombol Sign In, Create a Free Account dan Download yang dapat diakses pada menu halaman utama Mendeley. Sign In adalah menu untuk masuk jika sudah memiliki akun, Create a Free Account menu untuk membuat akun baru, dan Download merupakan menu untuk mengunduh Aplikasi Mendeley.

\section{Login pada Website Mendeley}

s.r. Mendeley

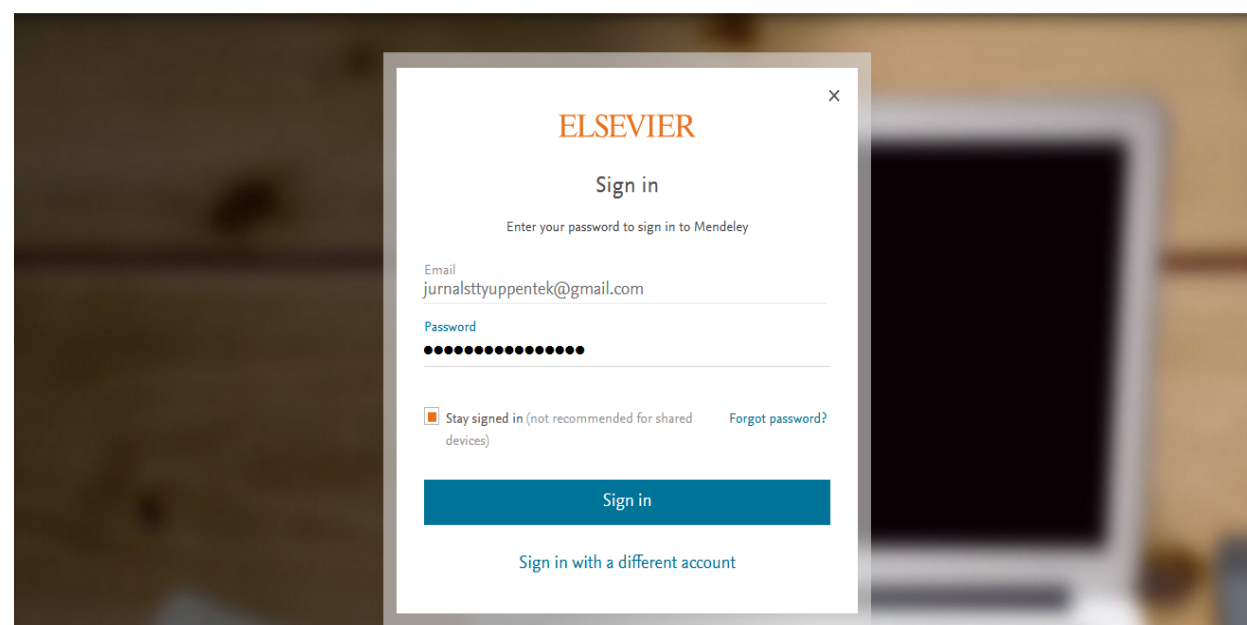

Gambar 4. Tampilan Menu Login

(Sumber : $\underline{\text { https://id.elsevier.com/as/QaxIF/resume/as/authorization.ping) }}$ 
Pada Gambar 4. merupakan tampilan dari menu Login, terdapat Form untuk mengisi username dan password. Dalam menu Login terdapat tombol Forgot Password untuk membantu user dalam lupa kata sandi.

\section{Masuk Halaman Menu Profile}

8
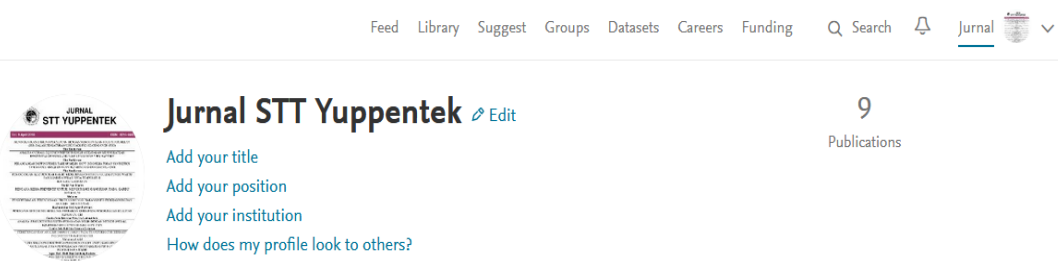

Jurnal STT Yuppentek $\theta$ Edit

9

Add your title

Add your position

Add your institution

How does my profile look to others?

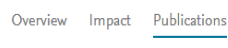

Publications $(9)+$ Add

Analisa Overall Equipment Effectiveness (OEE) dalam Meningkatkan Efektivitas Spinning and Take Up Machine 7 pfy Factory (Studi Kasus di PT Indonesia Toray Synthetics,

Tangerang)

Eko Kustiawan

Analisis Siklus Produktivitas Perkebunan Kopi Unit Usaha Strategis Malang sari Sebagai

Upaya Peningkatan Profitabilitas PTP

Agus Hari Hadi dan Gembong Baskoro

Gambar 5. Tampilan Menu Profile

(Sumber : https://www.mendeley.com/profiles/jurnal-stt-yuppentek/publications/)

Pada Gambar 5 merupakan Profile Jurnal STT Yuppentek, didalamnya terdapat tombol edit untuk menambahkan Add your title, Add your position, Add your institution. Kemudian terdapat publications yang terdapat tombol add publications dan karya ilmiah yang telah di posting.

\section{Mengisi Form Add Publication}




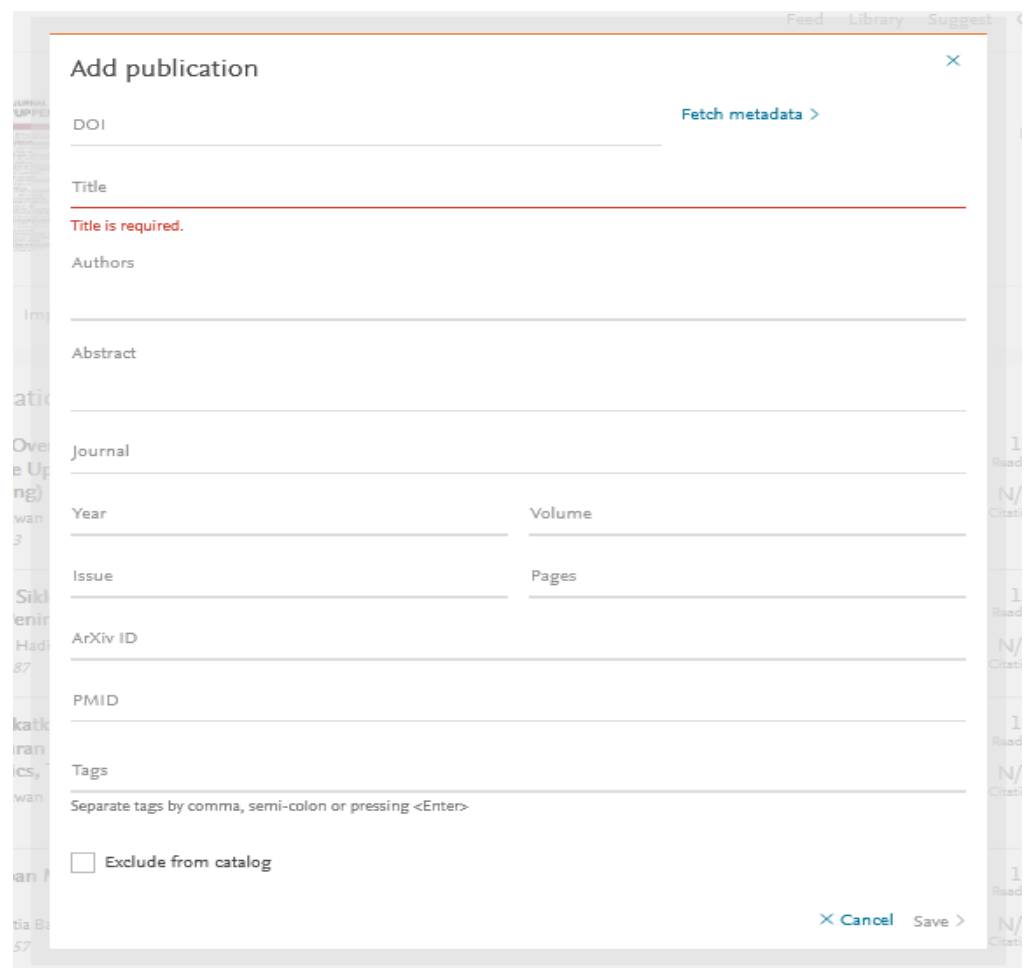

Gambar 6. Tampilan Menu Add Publications

(Sumber : https://www.mendeley.com/profiles/jurnal-stt-yuppentek/publications/)

Pada Gambar 6 merupakan tampilan dari menu add publications, didalamnya terdapat form DOI, Title, Author, Abstract, Journal, Year, Volume, Issue, Pages, arXiv ID, pmid, dan Tags. Form tersebut diisi untuk memposting karya ilmiah.

\section{Daftar artikel yang telah di Add Publications}

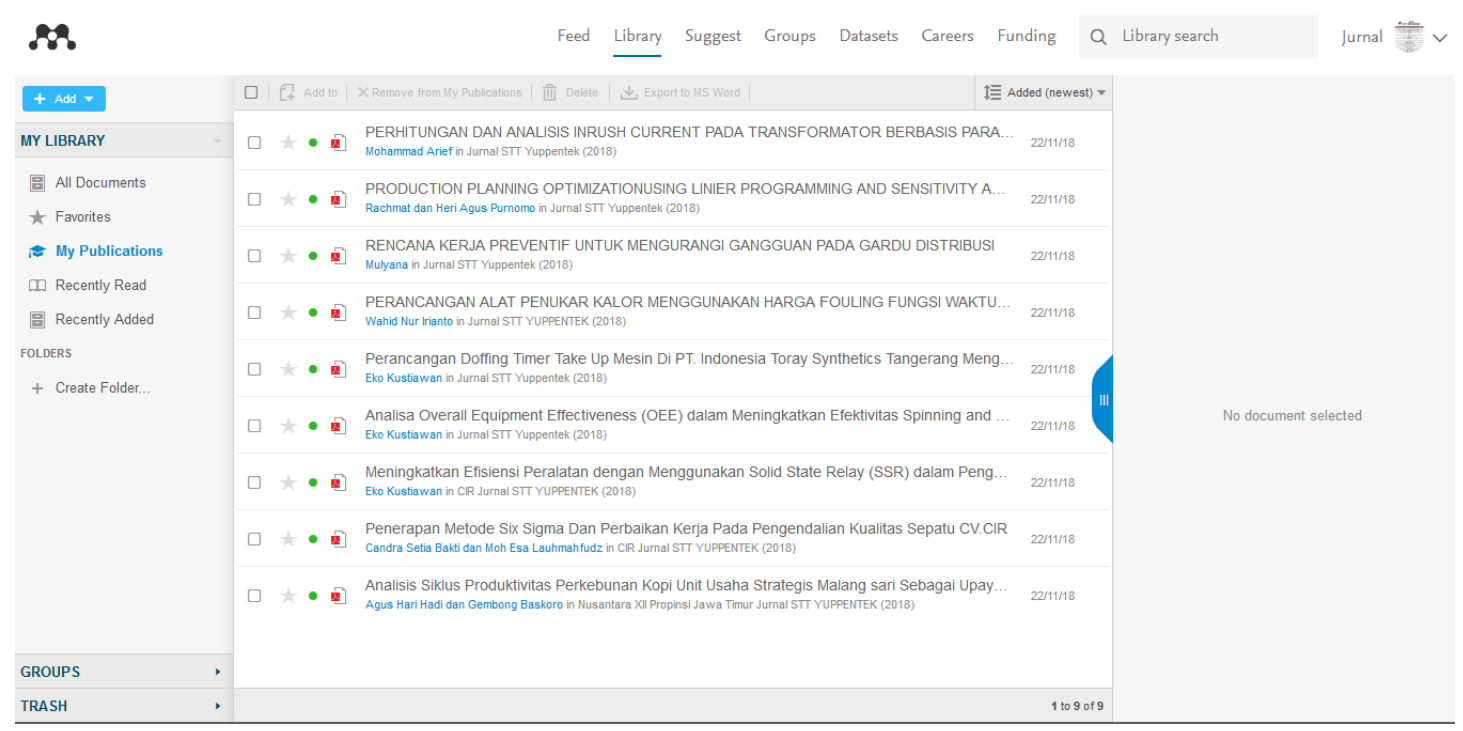

Gambar 7. Tampilan Menu library 
(Sumber : https://www.mendeley.com/library/)

Pada Gambar 7 merupakan tampilan menu Library, dalam menu Library terdapat semua dokumen yang telah diposting, dokumen dalam Groups dan dokumen yang sudah dihapus masuk ke dalam menu Trash.

\section{Menu Groups}

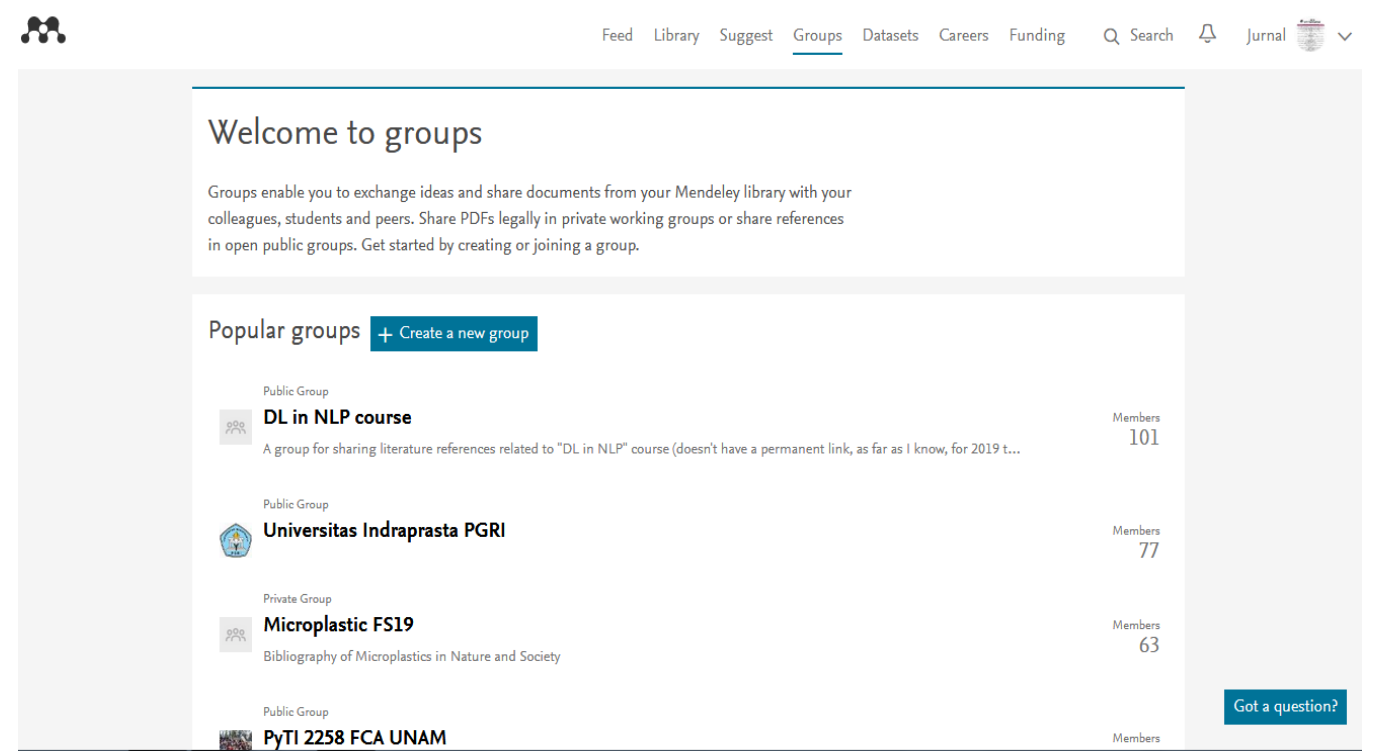

Gambar 8. Tampilan Menu Groups

(Sumber: $:$ https://www.mendeley.com/community/)

Pada Gambar 8 merupakan tampilan menu Groups, terdapat menu create new group untuk membuat Groups baru dan dapat juga dapat bergabung dengan Groups yang populer atau Groups direkomendasikan.

\section{KESIMPULAN}

Berdasarkan pembahasan dari penelitian diatas dapat disimpulkan bahwa Mendeley merupakan perangkat lunak yang dikhususkan untuk mengintegrasikan citation \& reference manager ke dalam sebuah jejaring sosial, dimana peneliti di berbagai belahan dunia dapat berkolaborasi dan melakukan sharing data penelitian. Seperti dalam penelitian ini yang menerapkan perangkat lunak Mendeley untuk karya ilmiah atau jurnal STT Yuppentek karena dinilai sangat membantu dalam mempermudah karena terdapat fitur Backup dan sinkronisasi data dari beberapa komputer dengan akun online, Import dokumen dan Import penelitian dari situs-situs eksternal seperti PubMed, Google Scholar, Terdapat Fitur Filtering dan juga fitur jejaring sosial antar peneliti. Dengan dilakukannya penelitian ini diharapkan dapat membantu pengelola Jurnal STT Yuppentek dalam meningkatkan popularitas karya ilmiah secara global.

\section{SARAN}

Untuk pengembangan selanjutnya maka ada beberapa saran yang dapat dijadikan sebagai referensi, diantaranya adalah : 
1. Perlu ditingkatkan indeksasi yang lain seperti Google Scholar, untuk meningkatkan popularitas dan akreditasi pada jurnal STT Yuppentek.

2. Perlu dilakukannya sosialisasi tentang indeksasi Mendeley kepada pihak STT Yuppentek agar mengetahui kelebihan tentang indeksasi tersebut.

\section{DAFTAR PUSTAKA}

[1] Rahmawati, R. (2018). ANALISIS INDEKSASI JURNAL ILMIAH BIDANG PERTANIAN INDONESIA DI DOAJ. Jurnal Pustaka Budaya, 5(2), 36-41.

[2] Rahmawati, C., Meliyana, M., Yuliana, Y., \& Zain, H. (2018). Pelatihan Software Mendeley Dalam Peningkatan Kualitas Artikel Ilmiah Bagi Dosen. JURNAL PENGABDIAN KEPADA MASYARAKAT, 8(1), 30-36.

[3] Darmalaksana, W. (2017). Panduan publikasi ilmiah: Perangkat aplikasi, standar penulisan dan etika kepengarangan.

[4] Junandi, S. (2018). Pengelolaan Jurnal Elektronik Bidang Perpustakaan Menuju Jurnal Terakreditasi. Pustabiblia: Journal of Library and Information Science, 2(1), 119-136.

[5] Rais, N. S. R., Supriati, R., \& Danti, S. I. (2018). Instalasi Open Journal System (OJS) Versi 3 Sebagai Pendukung Kegiatan Pengelolaan dan Publikasi Jurnal Ilmiah. Technomedia Journal, 2(2), 66-80.

[6] Sudaryono, S., Rahardja, U., \& Apriani, D. (2019). The CICES Journal Governance Performance Improvement on Quality of Current Issues (Case Study of STMIK RAHARJA). Aptisi Transactions On Management, 3(1), 57-64.

[7] Widyaningsih, N. M., \& Suryani, E. (2018). Analisis Kepuasan Pengguna Website Jurnal Online dengan Menggunakan Metode Webqual (Studi Kasus Buletin Penelitian Sistem Kesehatan). Teknikom: Teknologi Informasi, Ilmu Komputer dan Manajemen, 2(1), 1-5.

[8] Josi, A. (2017). Perancangan Dan Implementasi E-Jurnal Pada Unit Penelitian Dan Pengabdian Masyarakat (Up2m) Stmik Prabumulih. Journal Of Informatic Pelita Nusantara, 1(2).

[9] Rahardja, U., Harahap, E. P., \& Dewi, S. R. (2019). The Strategy of Enhancing Article Citation and H-Index on SINTA to Improve Tertiary Reputation. TELKOMNIKA (Telecommunication Computing Electronics and Control), 17(2).

[10] Windarto, A. P., Hartama, D., Wanto, A., \& Parlina, I. (2018). Pelatihan Pemanfaatan Mendeley Desktop Sebagai Program Istimewa Untuk Akademisi Dalam Membuat Citasi Karya Ilmiah. AKSIOLOGIYA: Jurnal Pengabdian Kepada Masyarakat, 2(2).

[11] Sunarya, A., Abimanyu, Y., \& Dewanto, I. J. (2018). Dasbor Pengontrolan Trafik Udara menggunakan BI Real-Time. SENSITEK, 1(1), 492-497.

[12] Abas Sunarya, P.O. \& Refianti, Rina \& Mutiara, Achmad \& Octaviani, Wiranti. (2019). Comparison of Accuracy between Convolutional Neural Networks and Naïve Bayes Classifiers in Sentiment Analysis on Twitter. International Journal of Advanced Computer Science and Applications. 10. 10.14569/IJACSA.2019.0100511. 